\title{
The Bid Section Division Model of Highway Renovation Project
}

\author{
Jingning Yan \\ Civil Engineering and Architecture School of Nanchang Hangkong University, Nanchang, Jiangxi, \\ 330063, China
}

2248602417@qq.com

Keywords: Bid section; Highway renovation project ; The mathematical model; Division; The total cost of construction

\begin{abstract}
Highway renovation project is a typical linear structure. Its features include big investment, big quantities and complicated construction. In order to attract more bidders to participate in the project competition, highway renovation project usually adopt the way of bid section division for bidding. The rationality on the bid section division of the highway renovation project can promote maximum efficiency of construction project.The paper analyse the principle on the bid section division of highway renovation project.The cost of highway renovation project related to the bid section division is called the total cost of construction. The total cost of construction includes the transaction cost of the project and the production cost of the project.By analyzing the relationship between the bid section division and the total cost of construction, the paper establishes the bid section division model of highway renovation project. The model can help the owner to determine the most economical scheme for bid section division of highway renovation project from a host of bid section division alternatives.
\end{abstract}

\section{Introduction}

According to the 2014 statistics bulletin of the transportation industry issued by the ministry of transport of the People's Republic of China,by the end of 2014, the national highway mileage of 446.39 thousands of kilometers, of which, the level of total length of 390.08 thousands of kilometers, accounting for $87.4 \%$ of the total mileage of highway in the nation. But with the increase of traffic flow, a lot of existing highway already cannot satisfy the requirement of capacity [1]. The existing some roads have been overwhelmed, hard to bear the needs of the development of the transportation road damage and blocking condition worse, the original road traffic capacity variation, comfort, economy of variation. Therefore, take the old road rebuilding to restore or increase its use function, is the effective solution. Some new high-grade highway network played a relief, however, the problems of original road rebuilding upgrade is imminent.

Highway renovation project has a large investment, large quantities, complex construction. To achieve this kind of project construction enterprises are rare. In order to choose the contractor to complete the project, highway renovation project usually adopt tender method to select contractor. But because of the characteristics of the highway renovation project, in order to attract more bidders to participate in the project competition, many highway renovation project usually adopt the way of dividing blocks for bidding [2].

Highway renovation project is a typical linear structure. It's up to dozens or even hundreds of kilometers. It involves more professional types. It contains the subgrade engineering, road engineering, bridge engineering, construction engineering and other professional engineering. Owners often divide blocks according to the characteristics of the project, considering the integrity, technical, special professional monopoly and design reasons, such as the division according to the work breakdown structure. Bid reasonably divided highway renovation project help to achieve the reasonable cohesion between blocks and tie-in, to reduce and avoid unnecessary money, time, quality loss and waste, so that the maximum benefits of the construction project. 


\section{The Concept of Highway Renovation Project Bid Section}

Highway renovation project bid section refers to the complete highway renovation project according to the implementation stage and project scope cut into sections, the engineering sections can be combined in a single or a tender tender object.

The generalized highway renovation project bid section is divided into staging bid section, engineering bid section, and partial bid section [3]. Large and super large construction projects due to reasons such as money supply, market demand and tender stage needs to be implemented in stages, this kind of stage tender bidding object is staging bid section. Engineering bid section is ready to put the construction of a whole or a whole project of a certain stage of the project is divided into several paragraphs and a tender tender or a single or combined object. General contractor after winning a bid project, according to the general contract conditions, can put the total package under the project is divided into several parts, even after the division is divided into several items project, and then put the part of the division of the engineering item engineering subcontracting the corresponding by means of bid invitation of the subcontractor, the branch of engineering bidding such as subcontract object, item project bid is called partial bid section.

\section{The Present Situation of Highway Renovation Project Bid Section Division}

The Bid Section Division is Too Thin. Part owner in the tender bid tend to divide too small is fine, to meet the bid tenderers for as much as possible, or even could be divided into independent component project to bid for the tender, give owner, supervision and construction unit itself has caused so much inconvenience.

The Specialization of Bid Section Division is High. In order to construction of some key parts or units for effective control and ensure engineering quality, pavement engineering, protection engineering and other professional engineering is bidded independently.

The Subjectivity of Bid Section Division is Strong. Some project as specified in the bidding process subcontract projects, from making the bidding contracting engineering points out these projects [4] and specify the specific construction contractors, and to the winning bid unit, also have to agree with the requirement of the tenderer.

\section{The Highway Renovation Project Cost}

The highway renovation project cost is according to determine the construction of the content, construction scale, construction standards, functional requirements and use requirement to the project completed and delivered the acceptance of all the required fees [5,6]. It includes construction and installation cost, equipment and instrument purchase cost, other engineering construction cost, budget reserve, construction loan interest and fixed assets investment adjustment tax. The compostion figure of highway renovation project cost is Fig. 1.

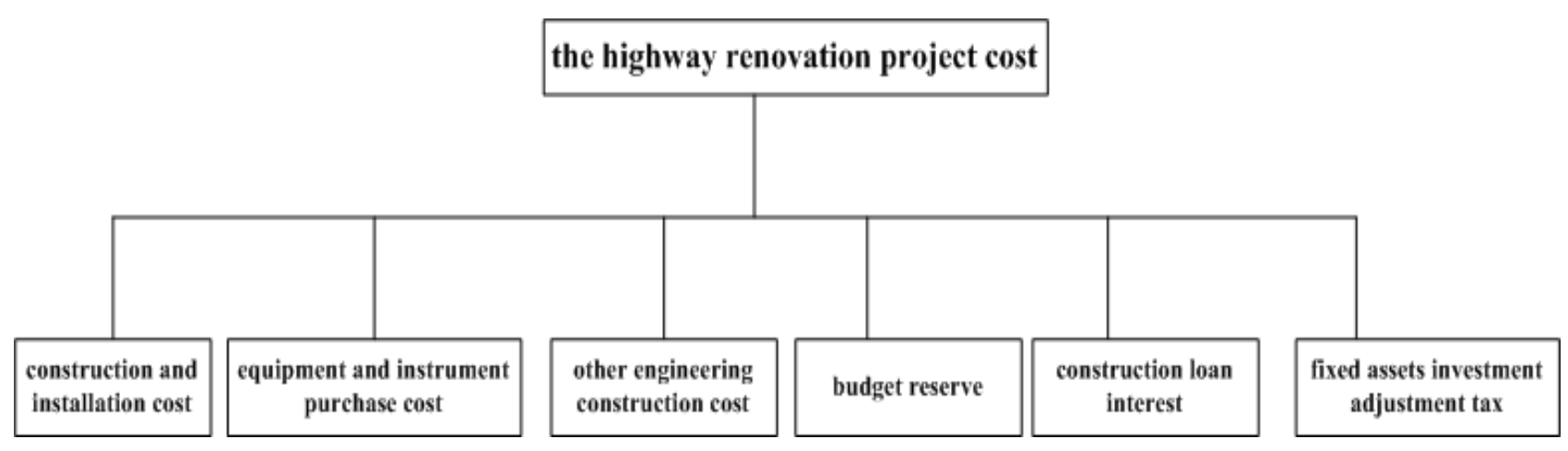

Figure 1. The compostion figure of highway renovation project cost 
Construction and installation cost is the engineering contract price, it formed the basis of the entire project cost pricing. Through analyzing the composition of the project cost, costs related to the bid section division is called the total cost of construction. The total cost of construction includes the transaction cost of the project and the production cost of the project. The production cost of the project is paid to the contractor the contract price, and is the construction and installation cost. the transaction cost of the project includes the costs of entrust a bidding agent, the cost of the contract negotiation, cost, the tender may be the risk of failure cost on supervision, construction project management fees, and does not constitute a project cost in the process of the performance of additional transaction costs. The mathematical expression of the total cost of construction is Eq. 1.

$$
C=T+P
$$

$\mathrm{C}$ represents the total cost of construction. T stands for the transaction cost of the project. $\mathrm{P}$ stands for the production cost of the project.

\section{The Impact of Highway Renovation Project Bid Section Division on the Project Cost}

The highway renovation project bid section division creats the physical interface. The physical interface includes two aspects of time and space. Time refers to the progress of the node in the process of project implementation, space refers to the division or physical connection between the lifting project. It is important to note the physical interface is inevitable. The number and complexity of it depends on the detailed design [7]. The bid section division produced a series of the contract interface. The bid section division interface is Fig. 2.

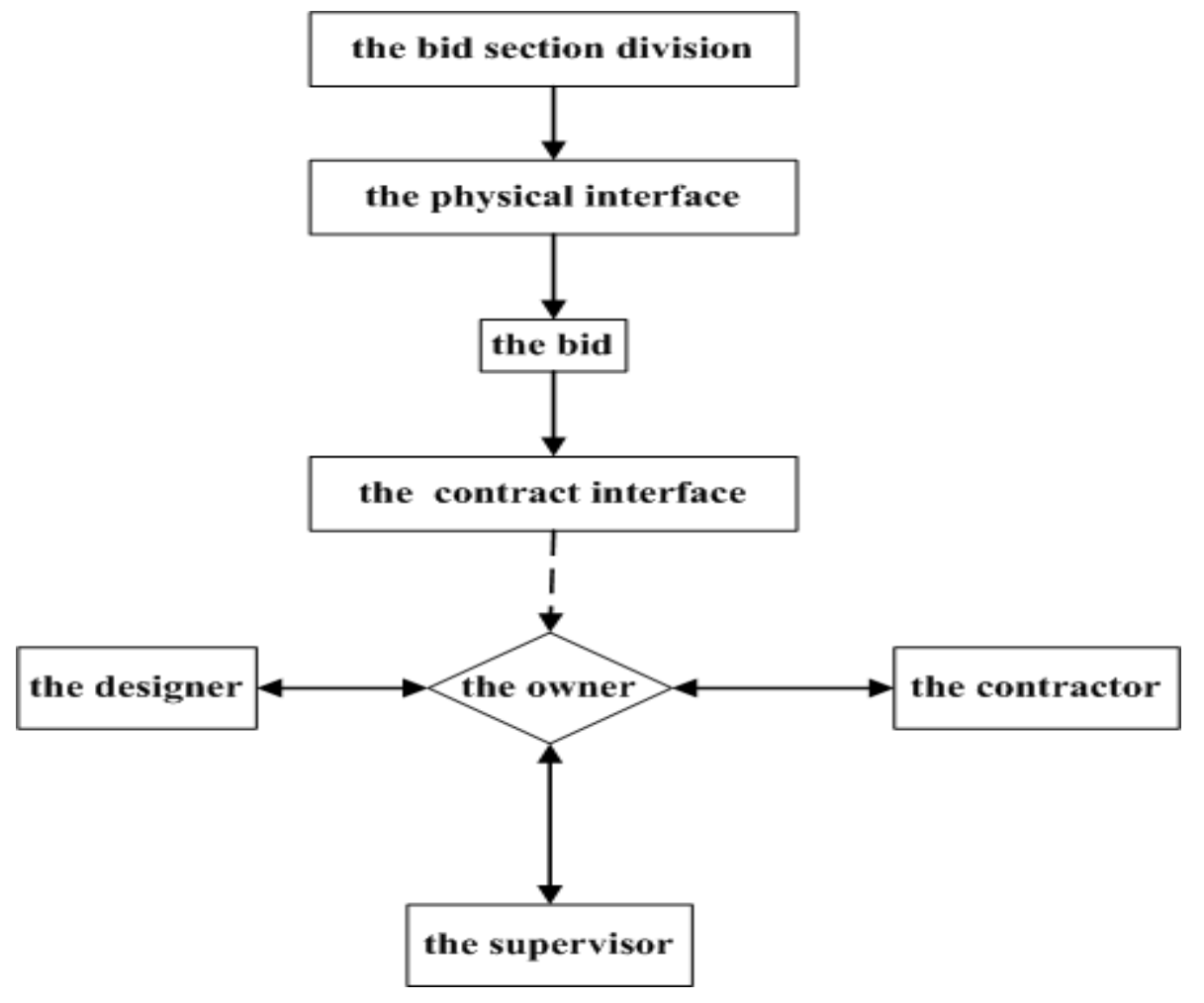

Figure 2. The bid section division interface

Bid section division play a key role in the control of project cost. When choosing bid section division scheme, decision makers will consider bid section division after the impact on the project cost. From the perspective of the use of bid section division and the relationship between the project cost in the process of project construction, analyzes the principles of bid section division [8]. Looking for in a bid section division to control the project cost is the most important in the process of dividing 
a number of factors, and use quantitative method to establish mathematical relationship between the number of blocks and the project cost, help policymakers intuitive selected bid section division divided the optimal solution.

\section{The Principle on the Bid Section Division of Highway Renovation Project}

The Specific Responsibility. It is the first principle of bid section division. Include the quality responsibility clear, clear responsibility, time limit for a project responsibility cost clear responsibility for security, environmental protection responsibility clear, etc. Including quality, cost, time limit for a project is the contractor's basic responsibility [9]. The contractor of the above basic duties in a bid to explicitly recognized basic decision basis is divided into bid lots correctly or not.

The Economy. Construction project is an economic activity, economic benefits is the primary goal of the pursuit of reasonable blocks partition can make full use of social resources, improve the ability of project risk, reduce the project cost.Should be in convenient construction, as little as possible to simplify the construction of temporary facilities, such as occupation of land resources, saving construction investment for the principle.

The Operability. It includes the maneuverability of the tender, the operability of construction management, project owner to determine the pre-tender estimate operability and money supply on the operability, etc.

The Systematicness. Construction project is an indivisible organic whole. The purpose of the bid section division is to work better. There are combining site and cross interface between each bid section, each bid section of the implementation of the process, should ensure the entire project investment, project construction joint plans and objectives such as quality and safety.One or more bid section divided in terms of local may not be optimal, but must conform to the requirements of the overall optimal.

The Competitiveness. Divided bid section size and the number of bid section of a project subject to tender, should be adapted to the number of potential bidders and the level of qualification, to form effective competition.

Project Management Convenience. Bid section division should also be combined with the management ability and the level of the construction unit, if the construction unit's own management ability is not enough, should be preferred way of general contract management, so that we can effectively reduce the bid section or because of the improper coordination between various waste and time limit for a project delay and other risks.

Ensure the Construction Quality and Schedule of the Project. The construction owner should be in-depth analysis and study of the project construction organization design, bid to avoid the excessive thinning, eliminate the unreasonable factors in the division, to facilitate the normal construction of construction enterprises, guarantee the smooth completion of the project construction.

\section{The Establishment of the Bid Section Division Model of Highway Renovation Project}

Through calculation and comparison the total construction cost directly related to the bid section division, the mathematical model of the scheme for dividing the bid can be determined [10]. The bid section division model of highway renovation project is Eq. 2.

$$
C=\min \left(\sum_{A_{i j} \in A_{I}} Z_{i}+\sum_{A_{I J} \in A_{i}} J_{i}+\sum_{A_{i j} \in A_{i}} P_{i}+\sum_{A_{i j} \in A_{i}} G_{i}\right.
$$

$\mathrm{C}$ represents the total cost of construction. $\mathrm{Z}_{\mathrm{i}}$ stands for the bidding agent fee of the "i" $i$ bid section division scheme. $\mathrm{P}$ stands for the production cost of the project. $\mathrm{J}_{\mathrm{i}}$ stands for the supervision fee of the "i" bid section division scheme. $\mathrm{P}$ stands for the production cost of the project. $\mathrm{P}_{\mathrm{i}}$ stands for the production cost of the " $i$ " bid section division scheme. $G_{i}$ stands for the construction project 
management fee of the "i $i$ " bid section division scheme. $A_{i j}$ stands for the " $j$ " bid section of the "i $i$ " bid section division scheme.

\section{Summary}

In the process of highway renovation project tender, owner should follow the principle of bid section division. By analyzing the relationship between the bid section division and the total cost of the highway renovation project, innovate the method to the bid section division of highway renovation project. From the perspective of total construction cost control, the study established the bid section division mathematical model of highway renovation project. The mathematical model can help the owner to determine the most economical scheme for bid section division of highway renovation project from a host of bid section division alternatives. Research result can provide quantitative basis for the decision-making for the tender for the owner and also can realize the rationality of the bid section division of highway renovation project.

\section{References}

[1] L.R.Zhang,Y.Liu and Z.Zhang:Water Resources and Hydropower Engineering, Vol. 43 (2012) No.12, p.67.

[2] P.Luo:Highway Construction Bidding and Tendering(China Communications Press, China,2015).

[3] J.Liu,Y.G.Tao,J.P.He and M.Q.Yang:Highways and Automotive Applications, Vol.5(2013) No.9, p.218.

[4] Z.R.Niu,S.Y.Teng and X.Z.Li: Mathematics in Practice and Theory, Vol.45(2015) No.1, p.50.

[5] C.M.Liu: Project Tendering and Bidding Management (The Peking University Publishing House, China,2012).

[6] S.H.Li: Urbanism and Architecture, Vol.26(2015) No8, p.267.

[7] D.Meng and P.Feng: Journal of Tianjin University, Vol.44(2011) No12, p.1088.

[8] X.Liu,J.Q.Geng and Y.Z.Bi: China Rural Water and Hydropower, Vol. 8 (2014) No.12, p.91.

[9] J.Yin: Project Management Technology, Vol.9(2011) No.6, p.60.

[10] X.Liu,Y.J.Wang, Y. Zhang and Y.Z.Bi: Journal of Wuhan University of Technology Information \& Management Engineering, Vol. 37 (2015) No.2, p.99. 